\title{
COMMENTARY
}

\section{The needle in the haystack: searching for biomarkers in acute respiratory distress syndrome}

\author{
David R Janz ${ }^{1 *}$ and Lorraine B Ware ${ }^{1,2}$ \\ See related research by Lin et al., http://ccforum.com/content/17/4/R155
}

\begin{abstract}
The acute respiratory distress syndrome commonly accompanies critical illness and is associated with significant morbidity and mortality. The implementation of life saving therapies is dependent on accurately identifying patients with this syndrome; however, beyond clinical definitions, we lack ancillary tests aimed at this specific diagnosis. This commentary discusses recent advances in the use of biomarkers to fill this diagnostic void.
\end{abstract}

In the previous issue of Critical Care, Lin and colleagues [1] report the utility of heparin-binding protein (HBP) in the diagnosis and prognosis of the acute respiratory distress syndrome (ARDS). ARDS is a common complication of critical illness and is associated with poor clinical outcomes, including both short- and long-term morbidity and mortality $[2,3]$. Several therapies are available to the clinician [4-6], but the implementation of these therapies is dependent on making an accurate diagnosis of ARDS. ARDS is undiagnosed in as many as $50 \%$ of patients $[7,8]$, a finding that may explain underutilization of lungprotective ventilation [9] and other therapies.

The differentiation of ARDS from cardiogenic pulmonary edema (CPE) adds additional complexity to the diagnosis of ARDS. This differentiation is currently made based on synthesis of available clinical data [10]. Although biomarkers such as troponin and brain natriuretic peptide have revolutionized the diagnosis and management of cardiac disease, intensivists have struggled to discover biomarkers of the same diagnostic utility in ARDS. The lack of clinically useful diagnostic biomarkers for ARDS may be a result of the complex interaction between the

\footnotetext{
*Correspondence: david.janz@vanderbilt.edu

${ }^{1}$ Department of Medicine, Division of Allergy, Pulmonary and Critical Care Medicine, Vanderbilt University School of Medicine, Nashville, TN 37232, USA Full list of author information is available at the end of the article
}

pulmonary endothelium, epithelium, interstitium, blood cells, and the inflammatory and coagulation cascades that characterizes ARDS [11], creating the so-called 'haystack' from which to find the troponin equivalent for ARDS.

The current study by Lin and colleagues focuses on HBP as a single biomarker for differentiation of early ARDS from CPE in critically ill patients. HBP is released from neutrophils during inflammation and increases vascular permeability. This dual role as a potential biomarker and injury mediator makes it an appealing candidate. In patients with traumatic injuries, higher levels of HBP early after trauma were associated with the development of ARDS [12]. The current study was a single-center, prospective observational cohort study in which HBP was measured within 10 hours of diagnosis of ARDS or CPE, diagnoses that were made by blinded, bedside clinicians. The study included 78 patients with ARDS, 28 with CPE, and 20 healthy volunteers. HBP levels were significantly higher in patients with ARDS compared to CPE and differentiated well between these patient groups (area under the receiver operating characteristic curve $(\mathrm{AUC})=0.815)$. Additionally, among patients with ARDS, HBP measured early in the course of illness was significantly higher in patients who did not survive compared to survivors; however, HBP was less helpful in predicting 30-day mortality $(\mathrm{AUC}=0.684)$.

This study has a number of strengths. The discriminating power of HBP, based on an AUC of 0.815, between patients with ARDS and CPE was relatively high compared to other single biomarker studies in ARDS [11]. Additionally, the biologic plausibility of HBP as an appropriate biomarker in ARDS and the prospective design strengthens this result. However, there are also limitations. Because only patients with ARDS or CPE were studied, the specificity of HBP for ARDS is not clear; elevated levels of HBP could also be related to infection, which was the primary cause of ARDS in the majority (74\%) of the ARDS group. Furthermore, patients were not ventilated with a standard low tidal volume approach. Since low tidal 
volume ventilation is a potent anti-inflammatory therapy [13], it is possible that HBP levels in this study were driven, in part, by a mechanical ventilation strategy and the findings may not be generalizable to patients treated uniformly with a low tidal volume strategy. The singlecenter design, small sample size, and numerous exclusion criteria make the results less generalizable to the overall, critically ill population with bilateral pulmonary infiltrates.

Although the results of the study by Lin and colleagues [1] are promising, it is unlikely that HBP is the single biomarker that has been sought to diagnose ARDS (that is, the needle in the haystack of pulmonary and systemic inflammation). In the future, HBP might be integrated into a panel of biomarkers that has a high discriminatory capability across a more diverse patient population at risk for ARDS. Because of the complex pathophysiology and clinical heterogeneity of ARDS, the biomarker 'panel' approach has already been useful for diagnosis in patients with traumatic injuries [14] and for prognosis in patients with established ARDS [15] and will likely gain favor especially as the cost and time needed for biomarker measurement decreases. As further insights are made into the pathophysiology of ARDS, the haystack of potential biomarkers for the diagnosis of ARDS will only expand. Prospective head-to-head comparison of multiple biomarkers such as HBP that can be combined in panels for diagnosis and prognosis will ultimately provide the most promise in aiding in the diagnosis and prognosis of ARDS.

\section{Abbreviations}

ARDS: Acute respiratory distress syndrome; AUC: Area under the receiver operating characteristic curve; CPE: Cardiogenic pulmonary edema; HBP: Heparin binding protein.

\section{Competing interests}

The authors declare that they have no competing interests.

\section{Authors' contributions}

DRJ and LBW both prepared and participated in the drafting and subsequent revisions of the manuscript.

\section{Acknowledgements}

The authors are supported in part by the Vanderbilt CTSA grant UL1 RR024975-01 from NCRR/NIH, NIH T32 HL87738, NIH HL103836, an American Heart Association Established Investigator Award, and Courtney's Race for the ARDS Cure and the Courtney Charneco Family.

\section{Author details}

${ }^{1}$ Department of Medicine, Division of Allergy, Pulmonary and Critical Care Medicine, Vanderbilt University School of Medicine, Nashville, TN 37232, USA. ${ }^{2}$ Department of Pathology, Microbiology and Immunology, Vanderbilt University School of Medicine, Nashville, TN 37232, USA.

\section{Published: 27 Sep 2013}

\section{References}

1. Lin Q, Shen J, Shen L, Zhang Z, Fu F: Increased plasma levels of heparinbinding protein in patients with acute respiratory distress syndrome. Crit Care 2013, 17:R155.
2. Rubenfeld GD, Caldwell E, Peabody E, Weaver J, Martin DP, Neff M, Stern EJ, Hudson LD: Incidence and outcomes of acute lung injury. N Engl J Med 2005, 353:1685-1693.

3. Herridge MS, Tansey CM, Matté A, Tomlinson G, Diaz-Granados N, Cooper A, Guest CB, Mazer CD, Mehta S, Stewart TE, Kudlow P, Cook D, Slutsky AS, Cheung AM, Canadian Critical Care Trials Group: Functional disability 5 years after acute respiratory distress syndrome. N Engl J Med 2011, 364:1293-1304.

4. Ventilation with lower tidal volumes as compared with traditional tidal volumes for acute lung injury and the acute respiratory distress syndrome. N Engl J Med 2000, 342:1301-1308.

5. Guérin C, Reignier J, Richard JC, Beuret P, Gacouin A, Boulain T, Mercier E, Badet M, Mercat A, Baudin O, Clavel M, Chatellier D, Jaber S, Rosselli S, Mancebo J, Sirodot M, Hilbert G, Bengler C, Richecoeur J, Gainnier M, Bayle F, Bourdin G, Leray V, Girard R, Baboi L, Ayzac L, PROSEVA Study Group: Prone positioning in severe acute respiratory distress syndrome. N Engl J Med 2013, 368:2159-2168.

6. Wiedemann HP, Wheeler AP, Bernard GR, Thompson BT, Hayden D, De Boisblanc B, Connors AF Jr, Hite RD, Harabin AL, National Heart, Lung, and Blood Institute Acute Respiratory Distress Syndrome (ARDS) Clinical Trials Network: Comparison of two fluid-management strategies in acute lung injury. N Engl J Med 2006, 354:2564-2575.

7. Ferguson ND, Frutos-Vivar F, Esteban A, Fernández-Segoviano P, Aramburu JA, Nájera L, Stewart TE: Acute respiratory distress syndrome: underrecognition by clinicians and diagnostic accuracy of three clinical definitions. Crit Care Med 2005, 33:2228-2234.

8. Fröhlich S, Murphy N, Doolan A, Ryan O, Boylan J: Acute respiratory distress syndrome: underrecognition by clinicians. J Crit Care 2013:0013700138.

9. Esteban A, Frutos-Vivar F, Muriel A, Ferguson ND, Peñuelas O, Abraira V, Raymondos K, Rios F, Nin N, Apezteguía C, Violi DA, Thille AW, Brochard L, González M, Villagomez AJ, Hurtado J, Davies AR, Du B, Maggiore SM, Pelosi P, Soto L, Tomicic V, D'Empaire G, Matamis D, Abroug F, Moreno RP, Soares MA, Arabi Y, Sandi F, Jibaja M, et al: Evolution of mortality over time in patients receiving mechanical ventilation. Am J Respir Crit Care Med 2013, 188:220-230.

10. Ware LB, Matthay MA: Clinical practice. Acute pulmonary edema. N Engl J Med 2005, 353:2788-2796.

11. Barnett N, Ware LB: Biomarkers in acute lung injury - marking forward progress. Crit Care Clin 2011, 27:661-683.

12. Johansson J, Brattström $O$, Sjöberg F, Lindbom L, Herwald H, Weitzberg E, Oldner A: Heparin-binding protein (HBP): an early marker of respiratory failure after trauma? Acta Anaesthesio/ Scand 2013, 57:580-586.

13. Parsons PE, Eisner MD, Thompson BT, Matthay MA, Ancukiewicz M, Bernard GR, Wheeler AP, NHLBI Acute Respiratory Distress Syndrome Clinical Trials Network: Lower tidal volume ventilation and plasma cytokine markers of inflammation in patients with acute lung injury. Crit Care Med 2005, 33:1-6. discussion 230-232

14. Fremont RD, Koyama T, Calfee CS, Wu W, Dossett LA, Bossert FR, Mitchell D, Wickersham N, Bernard GR, Matthay MA, May AK, Ware LB: Acute lung injury in patients with traumatic injuries: utility of a panel of biomarkers for diagnosis and pathogenesis. J Trauma 2010, 68:1121-1127.

15. Ware LB, Koyama T, Billheimer DD, Wu W, Bernard GR, Thompson BT, Brower RG, Standiford TJ, Martin TR, Matthay MA, NHLBI ARDS Clinical Trials Network: Prognostic and pathogenetic value of combining clinical and biochemical indices in patients with acute lung injury. Chest 2010, 137:288-296.

\section{$10.1186 / \mathrm{cc} 13025$}

Cite this article as: Janz and Ware: The needle in the haystack: searching for biomarkers in acute respiratory distress syndrome. Critical Care 2013, 17:192 